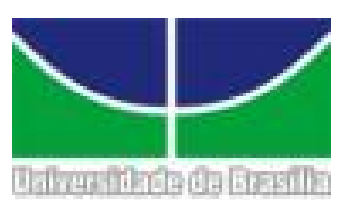

TURISMO SUSTENTÁVEL:
LIXO, ARTE E INCLUSÃO SOCIAL

Aluna: Bibiana Stohler Sabença de Almeida

Orientadora: Maria Angélica MadeIRA

Banca Examinadora: Mariza Veloso

Monografia apresentada ao Centro de ExcelÊnCia eM TURISMo da Universidade de Brasília como REQUISITO PARCIAL PARA A OBTENÇÃO DO CERTIFICADO DE ESPECIALISTA EM TURISMO: CULTURA E LAZER. 


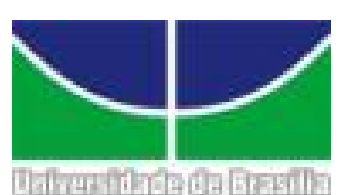

BRASÍLIA - DF, 30 DE JUNHO DE 2005

UNIVERSIDADE DE BRASÍLIA

Centro de ExcelênCia em Turismo

\section{TURISMO SUSTENTÁVEL: \\ LIXO, ARTE E INCLUSÃO SOCIAL}

Bibiana Stohler Sabença de Almeida 


\section{REFLEXÃo}

"SOMOS DEUSES E CRIADORES. TRANSFORMAR, CONSTRUIR, PRODUZIR, DESCARTAR E APROVEITAR. HOMEM CONTEMPORÂNEO CONJUGOU ESSES E MUITOS OUTROS. O MESMO DEUS do liXo É TAMBÉm AQUELES, o DEUS DA ARTE E DA VIDA." 
(de Bibiana Stohler Sabença de Almeida)

AgRADECIMENTOS

MEUS SINCEROS AGRADECIMENTOS AOS MEUS PAIS E

IRMÃOS, MINHA AVÓ E AO MEU GRANDE AMOR E COMPANHEIRO. AOS MEUS QUERIDOS PROFESSORES, PRINCIPALMENTE, A ORIENTADORA MARIA ANGÉLICA E A 
PROFESSORA MARIZA VeLOSO.

SUMÁRIO

ABSTRACT

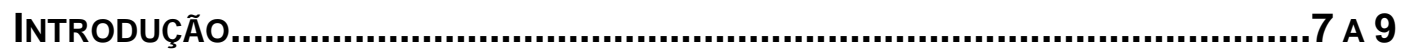

CAPÍTULO I - MODELO DE SUSTENTABILIDADE

1.1 - A SUSTENTABILIDADE NO TURISMO................................................... A 14

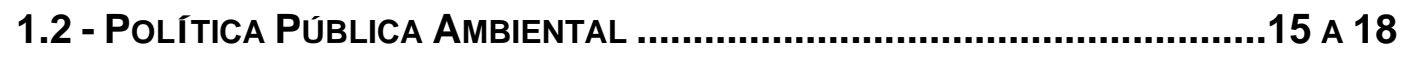

1.3 - A Reciclagem como dominante cultural: do lixo a aRTe .19 A 20

CAPÍtUlo II - PROJETO RECICLÃ (ESTUdO dE CASO)

1.1 - CONHECENDO O PROJETO RECICLÃ …………....................................... 25

1.2 - GenTE QUE SABE APROVEITAR O LIXO..........................................27 A 29

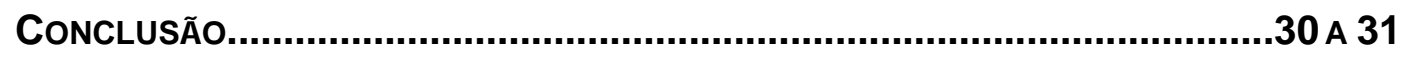

REFERÊNCIA BIBLIOGRÁFICA.................................................................. A 33

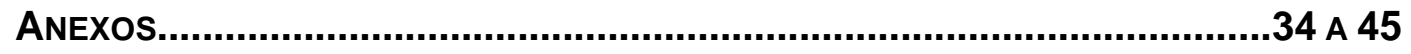

1.1 - DADOS DOS ENTREVISTADOS E QUESTÕES

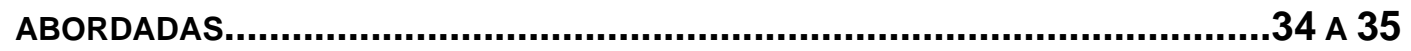

1.2 - "A Sustentabilidade é a Única Saída"; pUblicação da ReVISTa Eco

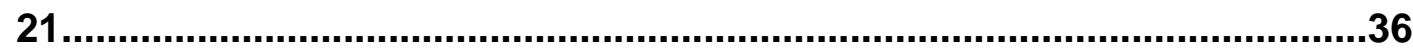

1.3 - “Dossiê Reciclagem”; publicaÇão da Revista Horizonte Geográfico

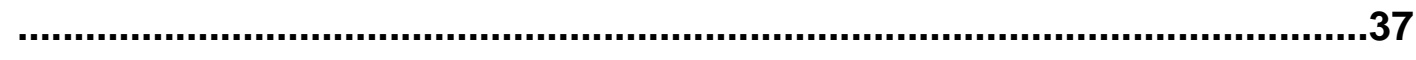

1.3 - CATÁlogo DE EXPOSIçÕes: Do LiXo AO

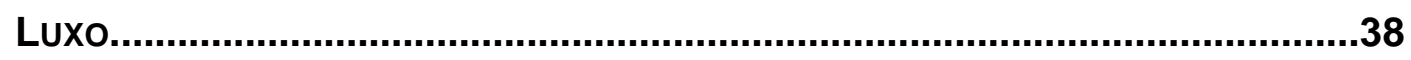

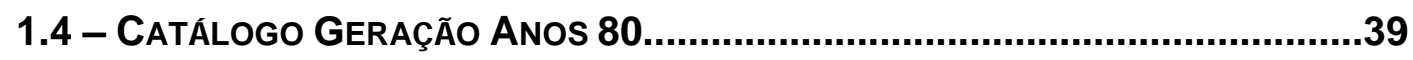




\section{AbStRact}

Este estudo pretende mostrar como a reciclagem do lixo, na sociedade contemporânea, pode ser utilizada como fator de mobilização para inclusão social e para fomentação do turismo sustentável. A transformação da chamada *matéria-prima social em bens de consumo abre um leque de oportunidades para 0 comércio regional, servindo de alicerce à implementação do turismo sustentável e promovendo o desenvolvimento individual e comunitário. Encontrei no Projeto Reciclã, da Associação de Artesãos do Meio Ambiente de Brasília/DF, uma estrutura integrada e amadurecida, o que foi decisivo para sua escolha como caso a ser analisado nesse trabalho.

This study it intends to show as the recycling of the garbage, in the society contemporary, can be used as factor of mobilization for social inclusion and fomentação of the sustainable tourism. The transformation of the call * social raw material in consumption good opens a fan of chances for the regional commerce, serving of foundation to the implementation of the sustainable tourism and promoting individual and communitarian the development. I found in the Reciclã Project, of the Association of Craftsmen of the Environment of Brasília/DF, an integrated and ripened structure, what he was decisive for its choice as case to be analyzed in this work. 


\section{INTRODUÇÃO}

Como utilizamos nosso lixo? Que fim damos a ele? O lixo pode gerar renda? Qual o papel da arte nas comunidades carentes? O que representa a reciclagem como elemento de inclusão social?

O presente trabalho tem por objetivo deixar claro a relação entre lixo, arte, inclusão social e turismo sustentável na sociedade contemporânea através do Projeto Reciclã. Para tanto, foi escolhido o Projeto Reciclã de Brasília-DF para apresentação como estudo de caso. Foram apontadas as atividades desenvolvidas pelas comunidades do Novo Gama, Capão das Negas e São Jorge. Para essas pessoas o lixo é sinônimo de sobrevivência.

A reciclagem, através da arte, tornou-se uma atividade lucrativa para comunidades desprivilegiadas. Por isso, é capaz de promover a inclusão social e fomentar o turismo sustentável local.

Para realizar este estudo recorri a autores e profissionais que atuam na área e tratam de temas relacionados, tais como: Ignacy Sachs, Fritjof Capra, Lester R. Brown, Maria do Carmo Lima Bezerra, Marcia Maria Facchina, Otto Ribas, Tânia Siqueira Montoro, Maria Luiza Mendonça, Lenita Nicoletti, Sandra Bernardes Ribeiro, João Gabriel Teixeira, Marcus Vinícios Carvalho Garcia, Rita Gusmão e Paulo Nogueira Neto. Estes estudiosos contribuíram para enriquecer meu olhar e serviram de base científica para esta monografia. Além disso, consultei sites e revistas especializadas para complementar com dados atualizados este trabalho.

Realizei também entrevistas com os idealizadores do Projeto Reciclã: Nicole Monteiro e Henrique Vila Verde que me forneceram preciosas informações para este estudo de caso (dados dos entrevistados e questões 
abordadas em anexos, $\left.n^{\circ} 1.1\right)$.

As entrevistas foram conduzidas com perguntas objetivas e diretas (o que é o projeto, quando foi fundado, quem são seus idealizadores, objetivos, sobre as atividades de reciclagem, resíduos utilizados, participação das comunidades, produto final para consumo, rentabilidade e beneficiados pelo programa).

Ao longo deste trabalho, conceitos-chaves como: sustentabilidade, educação e artista ambientais, matéria-prima social e reciclagem são definidos e contextualizados.

Outro ponto de observação, foi o processo de transformação do lixo, em todas as suas etapas, até o produto final de consumação. A valorização do lixo, através da arte, acontece quando o lixo ganha novo formato e sua reutilização, é investida de outros atributos e valores. O objeto transformado volta à sociedade através dos bens de consumo. Desta forma, inicia-se um novo ciclo de vida para aqueles produtos.

Nas comunidades carentes, a reciclagem pode assumir até um caráter estratégico, tornando-se a principal atividade de renda. As mulheres, participantes absolutas do projeto, aprendem um ofício e conseguem sustentar seus filhos. Além do que é ganho pela venda dos produtos finais, a Reciclã auxilia essas mulheres com cestas-básicas mensais.

Com credibilidade e retorno alcançados, a Reciclã contribui ao potencial turismo à região. Somente tais mulheres, específicas daquela localidade, usam determinados resíduos e produzem um tipo único de produto. Ponto de venda e comércio podem surgir na região a partir desta atividade, gerando novos postos de emprego. Os participantes do projeto Reciclã obtêm suas rendas com a venda dos produtos confeccionados, através das oficinas de reciclagem. 


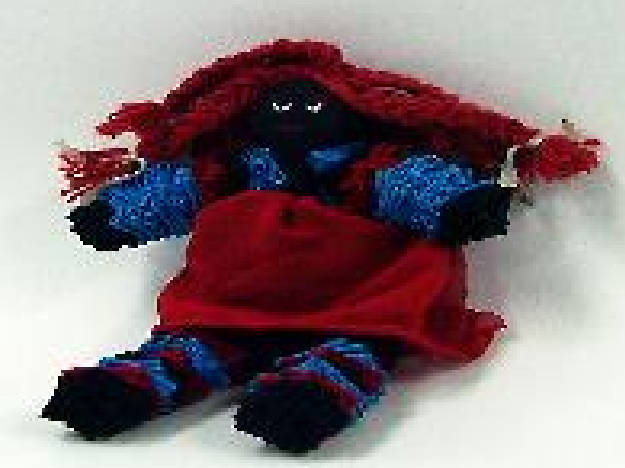

Figura 1

Boneca de retalhos - confeccionadas pela Comunidade do Novo Gama/DF

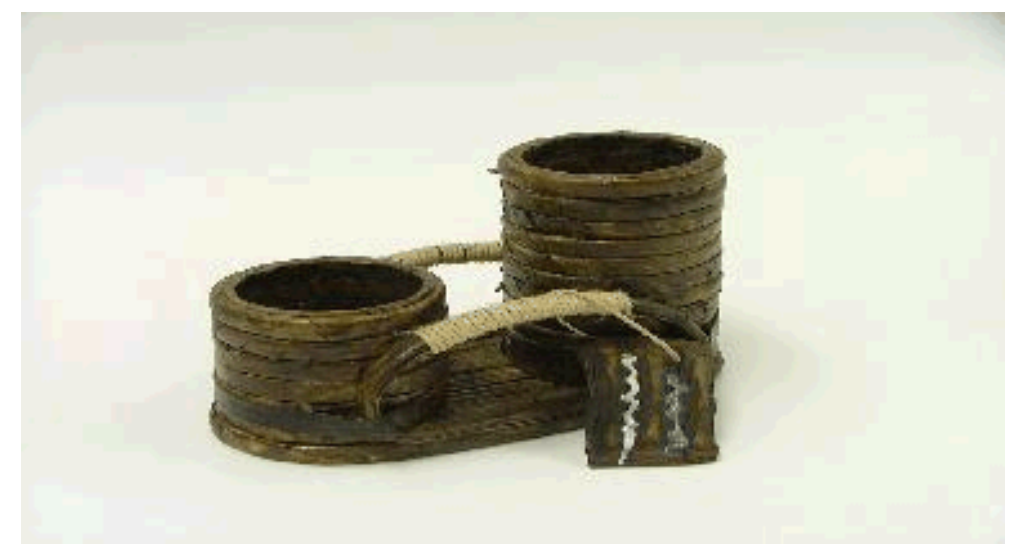

Figura 2

Porta treco - confeccionado pela Comunidade de São Jorge/GO 
Figura 1: Boneca de retalhos feita com sobras de malha e outros tecidos, tampa de garrafa (na cabeça), cola quente e costura.

Figura 2: Porta treco feito com jornal usado, corda de sisal, isolante, verniz e cola branca.

\section{CAPÍtULO I - MODELO DE SUSTENTABILIDADE}

\section{1 - A SUSTENTABILIDADE NO TURISMO}

É possível incentivar inclusão social, equilíbrio econômico, legislação protecionista e disponibilidade aos recursos naturais? Esta problemática tem sido discutida e avaliada por conhecedores de todas as nacionalidades. As relações e formas de interação entre o homem e o meio ambiente foram repensadas, sujeitas a uma adequação harmônica através do desenvolvimento sustentável.

Numa sociedade baseada na sustentabilidade, a solução proposta para diferentes problemas é: não comprometer as gerações futuras. Neste sentido, as alternativas devem contemplar o todo e suas partes, suas afinidades e trocas, tornando-as assim viáveis.

Uma passagem de Capra, ratifica o pensamento de preservação na sociedade sustentável:

“Lester Brawn, do Worldwatch Institute ${ }^{2}$, deu uma definição simples, clara e bela: Uma sociedade sustentável é aquela que satisfaz suas necessidades sem diminuir as perspectivas das gerações futuras."

Este, em resumo, é o grande desafio do nosso tempo: criar comunidades sustentáveis - isto é, ambientes sociais e culturais onde podemos satisfazer as nossas necessidades e aspirações sem diminuir as chances das gerações futuras." (1996, p. 24). 
1 A Teia da Vida - Uma Nova Compreensão Científica dos Sistemas Vivos. São Paulo. Editora Cultrix. 1996.

${ }^{2} \mathrm{O}$ Worldwatch Institute (WWI), sediado em Washington/USA, defende a idéia de uma sociedade ambientalmente sustentável, onde as necessidades humanas sejam atendidas sem ameaças à saúde da natureza.

Como complemento ao raciocínio apresentado, selecionei trechos do artigo *Sociedade Planetária Sustentável redigido por Capa e Callenbach, que esboçam panoramicamente uma futura sociedade sustentável, analisando práticas e interações de ordens econômicos, políticos, social e cultural:

“(..) Como seria, verdadeiramente, uma sociedade sustentável?(..) A sustentabilidade global requer uma drástica diminuição do crescimento mundial. As sociedades sustentáveis terão populações estáveis, como as que têm, atualmente, em 13 países europeus e o Japão. A população mundial deverá se estabilizar no máximo, em oito bilhões de pessoas. As economias sustentáveis não serão potencializadas por combustíveis fósseis, mas sim por energia solar e suas muitas formas diretas e indiretas; luz solar para aquecimento e eletricidade ${ }^{\star}$ fotovoltaica; energia eólica e hídrica(...) A energia nuclear deixará de ser usada devido às desvantagens e riscos econômicos, sociais e ambientais(...) Com as células fotovoltaicas, os lares, em todas as partes do mundo, chegarão a ser produtores tanto quanto consumidores de eletricidade.A produção de energia chegará a ser muito mais descentralizada e, por isso mesmo, menos vulnerável aos cortes ou apagões; isto será, também, compatível com as instituições políticas democráticas. Um sistema energético sustentável será mais eficiente energeticamente.(...) Tudo isto, hoje em dia, é possível graças às tecnologias já existentes." (Capra e Callenbach. 2005). 
* Sociedade Planetária Sustentável: artigo escrito pelo físico e teórico de sistemas vivos Fritjof Capra e pelo ambientalista Ernest Callenbach. Publicado na revista Eco 21. Edição 98. Rio de Janeiro. Tricontinental Editora. 2005.

** Fotovoltaica: é um tipo de energia originada pela energia solar. O prefixo "foto" que dizer produzido pela luz e o sufixo "voltático" significa eletricidade produzida por uma reação química. Usa-se o termo tecnologia FV.

Capra e Callenbach traçam um modelo de sociedade sustentável, mesmo que seus apontamentos sejam considerados utópicos. A observação de um outro modelo social, nos atenta à defasagem do modelo atual e à reflexão de novos conceitos e valores. Qual será a nova fonte de energia com o fim do petróleo? Os postos de gasolina se extinguirão? Como serão os automóveis do futuro? E os derivados do petróleo? O plástico, por exemplo, será substituído por outro material? Toda a cadeia do combustível fóssil, bem como a de seus derivados, estarão comprometidas com seus esgotamentos.

A consideração para outras fontes de energias não-poluidoras é uma preocupação eminente neste artigo. Mas como compatibilizar o modelo sustentável com as forças políticas? Como colocá-lo em prática?

A economia mundial baseia-se na exploração do combustível fóssil, logo as chances de implementação do modelo sustentável diminuem. Porém, o apontamento para uma outra relação social, modificando na base as esferas de poder, nos leva a refletir sobre a decadência do modelo atual e a repensar um futuro diferente.

Um outro autor que trata do tema é Ignacy Sanches, o defensor de cinco dimensões da sustentabilidade: social, econômica, ecológica ambiental, espacial geográfica e cultural.

$\mathrm{Na}$ sustentabilidade social, o equilíbrio é um fator importante ao crescimento social ordenado. A melhoria na distribuição de renda é necessária para que as camadas populares possam ter acesso as condições melhores de vida. O desenvolvimento humano é priorizado, 
servindo de base para orientação e reflexão.

Para que uma sociedade possa ser proporcionalmente igual, a aplicação de fundos públicos e privados devem ser bem implementada e revertidos para o bem comum. Na sustentabilidade econômica, o mercado interno deve ser contemplado, ajudando o micro-empresário. A economia interna precisa se fortalecer para gerar novos postos de emprego.

A preservação do meio ambiente também faz-se necessária. Aprender a utilizar e a potencializar o que os ecossistemas podem nos oferecer, é viabilizar fins para a sociedade, sem causar danos à natureza. Portanto, uma saída seria limitar o uso de elementos esgotáveis ou prejudiciais ambientalmente. Os produtos substitutos seriam renováveis, abundantes no meio ambiente e atóxicos. A reciclagem, bem como a coleta de seletiva de lixo, deve fazer parte do cotidiano social para reduzir a poluição. Outro ponto, são as pesquisas tecnológicas que poderiam ser eficientemente aplicadas ao desenvolvimento rural, industrial e urbano. Por fim, a elaboração de leis ambientais mais rigorosas à proteção, conservação e formas de manipulação.

$\mathrm{Na}$ sustentabilidade espacial geográfica, a relação rural-urbano seria saudável e equilibrada. Torna-se vital, desinchar as áreas metropolitanas com a distribuição do parque industrial no espaço rural. É importante manter ecossistemas fracos, porém preciosos ao equilíbrio ecológico e à diversidade ambiental. Criar uma reserva de proteção aos recursos naturais da biosfera, garantido a manutenção da biodiversidade das espécies. Pesquisas poderiam ser desenvolvidas para auxiliar no reflorestamento, na regeneração e no resgate da flora em extinção.

E a última, é a sustentabilidade cultural que traz conceitos de ecodesenvolvimento com possibilidades de solução para as cidades de super-populacões. Busca na interação harmoniosa do rural e urbano, modelos que se complementem, respeitando as especificidades das partes.

Considerar essas questões, nos permite compreender que a 
sustentabilidade é fundamental às práticas políticas sociais contemporâneas que estabelecem uma relação entre: sociedade e meio ambiente. Sachs, em uma breve citação, relata a falta de diálogo que existe entre os tomadores de decisão que são profissionais da área:

"O conceito de desenvolvimento eqüitativo em harmonia com a natureza deve permear todo nosso modo de pensar, informando as ações dos decisores e de profissionais de todos os tipos, inclusive a de funcionários burocráticos, que preparam e avaliam os projetos de desenvolvimento. A longa luta só será vencida no dia em que for possível, ao se falar do desenvolvimento, suprimir o prefixo 'eco' e o adjetivo 'sustentável'." (Sachs, 1987)*

O desenvolvimento sustentável aplica-se a todas as esferas sociais, uma delas é o turismo que ganhou importância relevante no cenário econômico. Com a globalização, o turismo se desenvolveu e passou ser destaque nas relações: inter-pessoal e social-ambiental, já que é também uma atividade humana. A harmonia destas relações permite a consideração de questões ambientais e a elaboração de efetivas políticas para prática do setor.

A reciclagem é destacada como prática que pode ser incorporada ao cotidiano, permitindo uma reestruturação no sistema em relação à consciência ecológica. Não mais teoria, e sim realizar ações, sobre o meio ambiente, criar de políticas públicas e legislações possíveis de serem cumpridas, visando o equilíbrio ecológico. 
* Relatório Nosso Futuro Comum: também conhecido como Relatório Brundtland, sobrenome da ex-primeira ministra da Noruega (Gro Harlem Brundtland) que presidiu a Comissão Mundial de Meio Ambiente e Desenvolvimento em 1987, época em que o documento foi redigido. O relatório previa a realização da Rio 92 e definiu o conceito de desenvolvimento sustentável.

\section{CAPÍTULO I - MODELO DE SUSTENTABILIDADE}

\section{2 - Política PÚBlica Ambiental}

A legislação brasileira incentiva a estrutura político-ambiental na administração de municípios? Que tipo de políticas públicas é aplicada para o desenvolvimento do turismo sustentável? Segundo a pesquisa *Informações Básicas Municipais (MUNIC), realizada pelo Instituto de Pesquisa Brasileiro de Geografia e Estatística (IBGE), em parceria com Ministério do Meio Ambiente, a falta de um planejamento ambiental está presente em 4.323 cidades brasileiras, trazendo sérios prejuízos na gestão do meio ambiente, na aplicação da sustentabilidade e na prática de técnicas de reciclagem.

Esta pesquisa, com base na temática "meio ambiente”, foi realizada em 5.560 municípios brasileiros e revelou que $88,8 \%$ das prefeituras de pequenos municípios do interior do país não possuem instrumentos para implementação de políticas públicas ambientais, faz-se notar na maioria das cidades. Tais dados indicam o despreparo na aplicação de estruturas político-ambientais.

Apenas 22,2\% dos municípios anunciaram participar do CONSEMMA - Conselho Municipal do Meio Ambiente e priorizar o planejamento ambiental em seus governos. Significa dizer que 1.237 cidades são atuantes na questão ambiental e colocam em prática a Agenda 21 local. 
Estas cidades estão localizadas nas regiões sul e sudeste.

* Informações Básicas Municipais (MUNIC): pesquisa descritiva, coletada em todas as prefeituras dos estados brasileiros, sobre os gastos públicos municipais, suas ofertas de serviços, desenvolvimento de programas sociais, saneamento básico, bem como toda a infra-estrutura urbana, administração de verba pública e planejamento municipal. Os últimos dados desta pesquisa são de 2002.

Para a realização desta pesquisa foram considerados critérios técnicos para uma avaliação precisa do cenário político-ambiental brasileiro. Estes critérios foram classificados em: 1. Pessoal capacitado e técnico no corpo administrativo das prefeituras na área do meio ambiente; 2. Campanhas institucionais, ações e programas voltados à população em incentivo à preservação do meio ambiente; 3. Aplicação da Agenda 21 local; 4. Fonte e investimento de recursos financeiros do meio ambiente; 5 . Aplicação de legislação ambiental municipal; 6. Verificação de instrumentos de gestão ambiental; 7. Existência de Unidades Municipais de Conservação da Natureza; 8. Diagnóstico do meio ambiente (estado de conservação e degradação); 9. Ações e resultados do gestor ambiental;

Desta forma foi possível averiguar nos 27 estados brasileiros que a política-pública ambiental não é priorizada. Em publicação divulgada pela revista JB Ecológico (Jornal do Brasil), em 4 de novembro de 2004, a coordenadora técnica da *Associação Nacional de Municípios e Meio Ambiente (ANAMMA), Ivani Zecchinelli declarou que:

"Dos 20\% (cidades com estrutura), apenas $10 \%$ são realmente aparelhadas. Muitos municípios até dispõem de uma ou duas pessoas trabalhando com meio-ambiente, mas elas não estão capacitadas." (Zecchinelli. 2004.) 
* Associação Nacional de Municípios e Meio Ambiente (ANAMMA): É uma instituição sem fins lucrativos, fundada em 1986 na cidade de Curitiba/PR que desenvolve ações para o fortalecimento de políticas públicas ambientais em todos os municípios brasileiros, preservando recursos naturais e aumentando a qualidade de vida da população. A ANAMMA está ligada diretamente ao Conselho Nacional do Meio Ambiente - CONAMA (Ministério do Meio Ambiente).

Tal fato, mostra o despreparo e a ausência de profissionais especializados na área, contribuindo para o desconhecimento e o não auxílio de fundos de financiamento nacional. Os municípios que não utilizam estes subsídios estão inviabilizados para implementar suas estruturas ambientais. Atualmente existem dois fundos de amparo ao meio ambiente: o Programa Nacional de Apoio à Gestão Administrativa e Fiscal dos Municípios Brasileiros (PNAF-M) e o Fundo Nacional do Meio Ambiente (ligado ao Ministério do Meio Ambiente) que foram criados para promover a consciência ecológica na gestão pública dos governos.

Para um aproveitamento máximo desses fundos, as administrações devem contemplar integrações entre: natureza, crescimento urbano, atividade econômica e desenvolvimento sustentável. As políticas públicas ambientais implicam um equilibrado planejamento ecológico, levando em consideração a relação homem e meio ambiente, tanto nas partes quanto no todo. Um olhar amplo e objetivo para a preservação da biosfera.

$\mathrm{Na}$ revista JB Ecológico (citada acima), o secretário de desenvolvimento sustentável do Ministério do Meio Ambiente, Gilney Vianadeclarou que: "O principal desafio dos novos gestores é ter uma visão mais integrada dos municípios. A Agenda 21 pode ser um instrumento de mobilização e nós podemos ajudar os novos gestores a dar esse passo. Há recursos para isso."

Os municípios que não desenvolvem planejamentos ambientais encontram dificuldades nas atividades econômicas associadas ao turismo. Primeiro, não existe desenvolvimento sustentável local. As estruturas de 
conservação do meio ambiente são insignificantes, prejudicando os investimentos de capacitação de pessoal. Segundo, a legislação ambiental é precária. Está previsto na Constituição Federal, em seu artigo 23, que União, Estados e Municípios têm obrigações conjuntas para conservação do meio ambiente. Apesar disso, a falta de definições claras sobre a competência política de seus governos emperra a máquina administrativa. A questão vem sendo apreciada pelo Congresso, mas ainda está longe de solução.

Com a implementação da Agenda 21 local, e a resolução dos problemas de competência administrativa, os municípios brasileiros teriam autonomia para desenvolver estratégias de responsabilidade ambiental. $\mathrm{O}$ amadurecimento do debate entre as autoridades e a sociedade civil sobre políticas públicas dedicadas ao setor é o melhor caminho para aplicação efetiva de um modelo de sustentabilidade. 


\section{CAPÍtULO I - MODELO DE SUSTENTABILIDADE}

\section{3 - A RECICLAGEM COMO DOMINANTE CULTURAL: DO LIXO A ARTE}

Qual o papel da reciclagem na sociedade contemporânea? Qual a relação entre reciclagem, arte e cultura? O conceito de reciclagem, que entende-se por atualização de conhecimentos e reaproveitamento de material usado, ganhou importância no cenário mundial. A reciclagem foi introduzida em nosso cotidiano no final do século $X X$ quando fortes movimentos de consciência ecológica foram valorizados.

Da necessidade de diminuir os resíduos sólidos produzidos pelo homem, a reciclagem surgiu para aumentar o ciclo de vida de materiais usados, bem como, devolvê-los à sociedade com nova utilização. Portanto, o lixo é o primeiro elemento de reciclagem.

O lixo é dividido em seco (materiais recicláveis: frascos de vidro em geral, latas de metal de alimentos e bebidas, tampinhas, arames, fios de aço, jornais, revistas, cadernos, caixas de papelão, caixas de leites e sucos, garrafas plásticas, tubos e canos, potes de creme e xampu) e orgânico (materiais não recicláveis: restos de alimentos, papéis higiênicos, embalagens laminadas para alimentos, etiquetas adesivas, fotografias, embalagens de aerossol, lâmpadas fluorescentes e até carcaças de pneus). A produção do lixo está diretamente ligada à cultura e ao grau de desenvolvimento de cada país. Geralmente em países do terceiro mundo, 
como é o caso do Brasil, a produção de lixo orgânico é maior. Já nos países do primeiro mundo, a predominância é do lixo seco.

Quando a produção de lixo orgânico é excessiva, é preciso criar mecanismos de controle da fonte geradora. Para tanto, a elaboração de um plano de gerenciamento do lixo urbano é essencial para amenizar problemas com o meio ambiente e de saúde da população causado pelo lixo urbano. Através da educação ambiental é possível conscientizar a sociedade sobre novas ações entre o homem e a natureza, buscando o bem estar social e a preservação do meio ambiente.

Além de sua associação com o lixo, a reciclagem passou a ocupar lugar de destaque nas manifestações artísticas, inovando conceitos de reutilização e de conteúdo, misturando arte, criatividade e originalidade.

O termo cultura sampler, que significa "releitura" de autores na recuperação de idéias e integração desses elementos, utiliza práticas de remixagem, tais como: colagens, sobreposições, diferentes texturas, novas técnicas e uso de materiais reciclados. A transformação de elementos que foram fragmentados de suas obras originais para compor outro objeto, formam um novo padrão estético. A reciclagem ganha um "status” positivo, qualificando a reutilização do lixo.

Como uma obra pode ter a produção de vários autores, os direitos autorais destas novas construções ficam perdidos, pois esta prática caracteriza a produção coletiva e anônima.

Porém, tudo isto foi possível graças à tecnologia digital que recuperou diversas produções culturais, entre elas: músicas, textos, fotografias e pinturas, permitindo uma completa manipulação e mistura de informações. Assim também, aumentou a velocidade de transformação e troca de dados nos meios de comunicação, principalmente no meio internet, onde novos softwares e programas como: webcam, chats, conversas instâneas, skype (voz por IP), blogges entre outros, foram desenvolvidos para aproximar e conectar pessoas, ajudando a compartilhar outras culturas e descentralizando o conhecimento técnico. 


\section{CAPítulo II - PROJETO RECILÃ(ESTUDO dE CASO)}

\section{1 - ConHeCENDO o PROJeto Reciclã}

Fundada há três anos, a Associação de Artesãos do Meio Ambiente é integrada atualmente por quarenta **artistas ambientais, que atuam em quatro comunidades carentes: Santo Antônio do Descoberto/GO (Grupo Reintegra), Novo Gama, Capão das Negas (na divisa com a Estação Ecológica de Águas Emendadas) e São Jorge, na Chapada dos Veadeiros. No total, são aproximadamente duzentas pessoas envolvidas no projeto entre artistas e pessoas das comunidades. A primeira fase do processo de valorização do "lixo" em arte acontece em oficinas de reciclagem, onde os membros dessas comunidades aprendem, com o acompanhamento de profissionais de artes plásticas, a manusear as matérias-primas, agregando valor cultural e novo uso. Dentre os materiais processados destacam-se: sobras de malha, garrafas PET, tampas de plástico, papel jornal, papelão, cacos de vidro, arames usados e pedaços de metal. Materiais que iriam para o lixo, sem qualidades aparentes. Após receber tratamento, esses objetos servirão para a produção de jóias, peças decorativas, desde utensílios domésticos até bonecas de pano, bolsas e prendedores de cabelo. Numa segunda fase, em ateliês de criação (geralmente em galpões dos centros comunitários locais), os alunos começam confeccionar os materiais. Nas aulas de oficina de reciclagem, os artistas ambientais ensinam técnicas 
(corte e costura, colagem, pintura entre outros) para processar os resíduos e transformá-los no produto final acabado. Na terceira fase do processo, esses bens (já valorizados e reaproveitados) ganham as ruas em exposições e mostras nos principais pontos de concentração de pessoas (escolas locais, centros comunitários, universidades, shoppings, centros culturais entre outros). A renda gerada pela venda desses produtos é revertida aos participantes do projeto. Outro ponto importante, é o cuidado com o meio ambiente nas comunidades carentes, onde ***educação ambiental é primordial. Preservação e manutenção fazem parte da proposta ambiental desenvolvida pelo Reciclã. E finalmente, os membros das comunidades se tornam agentes multiplicadores do conhecimento adquirido na atividade de reciclagem. Ainda orientados pela Associação, alguns desses membros iniciam novos trabalhos com pessoas da própria comunidade. Sem saber, colocam em prática o conceito de auto-sustentabilidade. Além disso, o desenvolvimento do artesanato local, por sua peculiaridade, tende a agregar valor cultural, gerar negócios, criar novas oportunidades de empregos e atrair o turismo. Numa sociedade onde os resíduos são mal aproveitados, é possível (re)utilizar o lixo e favorecer na realização de atividade rentável às comunidades carentes. Procurei chamar a atenção para questões contemporâneas que interessam diretamente a essa reflexão, quais sejam: o turismo sustentável, a reciclagem e a inclusão social.

O lixo também é um bom negócio!

Matéria-prima social: são resíduos sólidos do lixo que podem ser 
reaproveitados por grupos sociais desprivilegiados.

** Artistas ambientais: são profissionais que reciclam resíduos sólidos, criando bens artísticos e aplicando conceitos de educação ambiental. Esses materiais retornam à sociedade com novas utilizações e valores.

*** Educação ambiental: conceitos como conservação e subsistência são defendidos para a conservação do meio ambiente, respeitando o ciclo de vida dos materiais a serem reciclados.

O Projeto Reciclã nasceu em São Sebastião/DF, através de uma aula realizada em parceria com o SEBRAE, em 2002. Quando o curso terminou, o projeto não obteve apoio e para dar continuidade ao trabalho nesta comunidade. Fundou-se a Associação de Artesãos do Meio Ambiente, em dezembro deste mesmo ano. Nicole Monteiro e Henrique Vila Verde são os idealizadores do projeto. Ambos publicitários, eles desenvolveram inúmeras propostas voltadas à reciclagem, educação ambiental e responsabilidade social.

A Reciclã é uma associação formada com o intuito de propagar a conscientização ambiental, transformando o lixo em arte para integrar grupos sociais marginalizados.

Atualmente, a Associação de Artesãos do Meio Ambiente de Brasília conta com a participação de quarenta artistas ambientais que ministram aulas a quatro comunidades carentes:

1 - Grupo Reintegra em Santo Antônio do Descoberto/GO (formado por dependentes químicos);

2 - Dois grupos do Novo Gama (cidade satélite do DF);

3 - Capão das Negas (localizado às margens da estrada que liga Brasília/DF a Chapada dos Veadeiros/GO);

4 - São Jorge (na Chapada dos Veadeiros/GO);

Um dos objetivos da Reciclã é sensibilizar a sociedade para a 
reutilização e reciclagem dos resíduos do lixo. Segundo Vila Verde, o importante é agregar valor ao produto final transformado: "Buscamos através da arte mostrar que tudo pode ser reciclado, transformando aquilo que iria para o lixo em novos produtos de consumo, seguindo um alto padrão de qualidade e acabamento." (Entrevista 1).

Embora o projeto exista somente há três anos, foram realizadas mais de dezoito exposições em locais de grande público, tais como: Conjunto Nacional (na semana do Meio Ambiente), Supermercado Extra (Asa Norte), Pão de Açúcar (Lago Sul), SIA Casa Shopping, Ministério do Meio Ambiente, Conferência Nacional do Meio Ambiente, XXIII Conferência Nacional de Zootecnia, NOVACAP, Tribunal de Contas do DF, Ministério da Educação, Ministério das Minas e Energia, Ministério dos Transportes, STF (Supremo Tribunal Federal), Ministério da Justiça, Ministério das Comunicações (além da exposição, foram feitas oficinas de enfeites natalinos em reciclagem), Jardim Botânico de Brasília, Correio Braziliense e UNICEUB. Atualmente, a Reciclã expõe seu material no Restaurante Nó na Madeira, localizado na Vila Planalto/DF, com exposição permanente e, ainda disponibiliza cursos na Câmara dos Deputados.

Além de trabalhos realizados com as comunidades carentes, a Reciclã também ministra oficinas em escolas privadas do DF, de $5^{\mathrm{a}}$ a $8^{\mathrm{a}}$ séries, ensinando educação ambiental, reciclagem e arte através de *kits escolares. Cerca de duzentas crianças já foram beneficiadas com o programa. 
*Kit escolar: sobras de malhas dentro de garrafas PETs. As crianças aprendem a confeccionar esse material residual, transformando-o em um outro material com nova utilização.

Grande parte do material utilizado pela Reciclã vem da doação. São pedacinhos de pano, garrafas plásticas, papelão, sucatas entre outros objetos doados tanto por pessoas físicas quanto por empresas privadas. De acordo com Monteiro, as pessoas se encantam pelo trabalho da Reciclã e por isso contribuem com alguma doação: "Precisei de duzentas garrafas PETs para fazer a oficina nas escolas. Liguei para as pessoas que já conhecem a gente, dentro do meu condomínio, e saí pedindo: gente não joga fora garrafa de PET! E aí eu passei e fui buscando. Outro exemplo, é a malha, para mim não falta. Sempre tem alguém me ligando para doar." (Entrevista 2).

Os resíduos encontrados em cada comunidade passam, primeiro, pela inspeção e análise da Reciclã. São averiguados origem, tipo de material, conservação e possíveis reutilizações. Posteriormente, para serem aproveitados, inicia-se o processo de criação.

$\mathrm{Na}$ produção os participantes do projeto, em sua maioria mulheres, confeccionam as peças, separando resíduos, cortando malhas e costurando. Nas oficinas de aprendizagem, muitas histórias são contadas, casos de espancamento, fome e miséria. As aulas funcionam também como terapia de grupo. A atividade ganha reflexão e auto-estima. Como incentivo, cada participante recebe uma cesta-básica doada pela própria Reciclã. Monteiro faz um apontamento interessante para a mudança de comportamento: "Quando você começa a mexer com o lixo, e transforma o lixo, você se transforma junto. Isso acontece com qualquer pessoa que trabalha com reciclagem." (Entrevista 2$)$. 
Essas mulheres recuperam sua dignidade e aprendem um ofício. $\mathrm{O}$ trabalho artístico da Reciclã está fortemente vinculado à responsabilidade social. As famílias participantes do projeto são reeducadas, melhorando suas relações inter-pessoais.

Outro ponto importante é a geração de renda para essas famílias. Com a atividade de reciclagem, surgiram "encomendas de trabalho". A proposta da Reciclã com as comunidades tornou-se conhecida, dando credibilidade ao projeto. Como explica Monteiro: "Elas não acreditavam e só passaram, realmente, a acreditar quando surgiram as encomendas." (Entrevista 2).

O lixo tornou-se necessário, matéria-prima social, que está diretamente ligado às atividades realizadas nas comunidades carentes. Para que os resíduos não cheguem ao seu destino final, que é o lixão, estes materiais são selecionados e manipulados antes. A proposta é diminuir os resíduos, aumentando seu aproveitamento. A reutilização destes objetos se dá através da arte. O lixo ganha forma. Respeita-se o ciclo de vida dos produtos, valorizando seus potenciais. Vila Verde menciona a importância da arte para conscientização é para uma nova reflexão: “Utilizamos a arte como veículo para a educação ambiental e inclusão social.” (Entrevista 1)

O projeto Reciclã visa à transformação permanente dos resíduos, desenvolvendo atividades de reciclagem nas comunidades carentes. O que implica num complexo de valores individuais, morais e sociais que incorporam um cenário em construção. 


\section{CAPítulo II - PROJETO RECILÃ(ESTUDO dE CASO)}

\section{2 - GENTE QUE SABE APROVEITAR O LIXO}

Da idéia inicial de trabalhar com o lixo, Monteiro passou a divulgar e agregar conceitos mais elaborados nas atividades de reciclagem. A educação ambiental serviu de base para explicar o aproveitamento máximo dos resíduos, os processos de transformação do lixo, a reutilização de novos objetos, o produto final para consumo e o fator lucro às comunidades.

Em São Sebastião, todas as mulheres que integraram ao Projeto Reciclã eram domésticas. No Novo Gama, muitas mulheres não tinham ocupação, e com o projeto passaram a ter uma renda (não fixa) com a venda dos produtos confeccionados. Elas precisam de um incentivo para as atividades de reciclagem, pois muitas passam fome. Monteiro conta como é sua linha pedagógica e como trabalha psicologicamente os sentimentos destas mulheres: "Vamos cortar as malhas para fazer braços e pernas das bonecas, comecem a pensar em um monte de coisas ruins, pensem no marido, aquele cretino! Cortem todas as desgraceiras da sua vida!” (Entrevista 2).

Posteriormente, há uma segunda fase na qual, Monteiro fala dos sonhos. Neste processo de produção, as mulheres costuram os pedaços das bonecas, dando novas formas e utilização aos resíduos do lixo. Para estimulá-las Monteiro faz perguntas como: Qual o maior sonho da sua vida? 
Se você tivesse muito dinheiro o que faria? As respostas afirmam o panorama de miséria e desigualdade social nestas comunidades: "Uma falou que o maior sonho da vida dela era nunca mais ver o filho chorar de fome. A outra disse que nunca mais queria sentir dor de fome. Uma terceira disse que seu sonho era que o marido nunca mais tocasse nela porque apanhava muito dele. O mais leve, foi quando uma disse que o maior sonho da vida dela era comer um pote de sorvete de creme, sentada no sofá, vendo televisão.” (Entrevista 2).

São mulheres sofridas, mas lutadoras. O trabalho social da Reciclã garante que cada uma destas mulheres não passe fome, através de cestasbásicas para garantir a presença nas oficinas de reciclagem. "Ninguém pode trabalhar sentindo fome ou pensando que os filhos estão em casa passando fome." (Entrevista 2). Estas mulheres querem trabalhar, ter um ofício e ganhar seu próprio dinheiro.

Um outro exemplo são os dependentes químicos do Grupo Reintegra em Santo Antônio do Descoberto/GO que começaram a participar das atividades de reciclagem com finalidade de recuperação clínico-mental. Este centro foi fundado em 1995, e antes da entrada do projeto, a média de recuperação era de duas pessoas num grupo de dez. Quando o projeto passou a fazer parte do processo de recuperação desses internos, a média subiu para seis. Nesta comunidade, vinte pessoas são beneficiados com o projeto.

Para Monteiro a melhora de comportamento acontece porque a reciclagem é capaz de mudar as pessoas. "Você está numa depressão profunda, e começa a mexer com o lixo. Aí o resultado final fica bonito. Você se sente orgulhoso. Por um acaso, vende aquele produto. Ganha um dinheiro que tem um valor especial.” (Entrevista 2).

$\mathrm{Na}$ comunidade do Novo Gama, no início das oficinas, as mulheres assistiam as aulas sujas e com odor muito forte. Monteiro relatou que a primeira semana não foi fácil porque elas tinham dificuldades em aprender as atividades. Com o andamento das aulas, essas mulheres passaram a 
acreditar no que estavam produzindo e foram se transformando. De banho tomado, higienizadas e cabelos penteados, elas começaram a chamar a atenção de assistentes sociais e psicólogos da prefeitura. O projeto acertou no comportamento deste grupo, transfigurando sua conduta para melhor. "Elas ficaram irreconhecíveis. A diferença foi grande, tanto que a prefeitura nos convidou para fazer parte de um outro projeto de auto-estima e dignidade.” (Entrevista 2). São mulheres que buscam reintegração social, às vezes, famílias inteiras, como é o caso de D. Faustina. Participante ativa nesta comunidade, ela conta com a ajuda de mais quatro filhas que também participam do projeto. Atualmente, são vinte e cinco mulheres beneficiadas nesta comunidade.

Além do resgate psicológico, as comunidades que fazem parte do projeto, voltam à sociedade. Surgem encomendas, ganho de renda e aprendizagem de um ofício. Com a inclusão social, a *cidadania pode ser exercida, beneficiando estes grupos sociais. Portanto, o resgaste da cidadania está diretamente associado à melhora de condição social do indivíduo. Quando a prática da cidadania é exercida pelo ${ }^{\star *}$ cidadão tem consciente de seus direitos e deveres. Este pensamento pode ser exemplificado numa breve citação de Dallari, Direitos Humanos e Cidadania. São Paulo: Moderna, 1998. p. 14, na qual verificamos que: "A cidadania expressa um conjunto de direitos que dá à pessoa a possibilidade de participar ativamente da vida e do governo de seu povo. Quem não tem cidadania está marginalizado ou excluído da vida social e da tomada de decisões, ficando numa posição de inferioridade dentro do grupo social."

Trabalho, cidadania e dignidade são valores reconquistados por mulheres que encontraram na atividade de reciclagem, a possibilidade de melhorar suas vidas. Ao utilizar o lixo, restabeleceu-se o laço social. 
*Cidadania: "Qualidade ou condição de cidadão". Mini Dicionário Luft. $2^{\circ}$ edição. São Paulo: Ática, 1991, p. 137.

*Cidadão: "Indivíduo no gozo de seus de seus direitos civis e políticos."Mini Dicionário Luft. $2^{\circ}$ edição. São Paulo: Ática, 1991, p. 137.

\section{CONCLUSÃo}

A partir do estudo do caso apresentado foi possível concluir que existe viabilidade para o desenvolvimento sustentável nas comunidades carentes, através da valorização do lixo, sua transformação em arte e sua finalização como bem de consumo. Este produto acabado é reutilizado, permitindo que a sociedade possa incorporá-lo em um novo ciclo de uso. O projeto Reciclã nos mostrou que a atividade de reciclagem pode ser rentável e que atrás dela, grupos sociais desprivilegiados podem ser incluídos socialmente.

Até o momento, o desenvolvimento das atividades de reciclagem destas comunidades têm sido realizado, em sua maioria, pela iniciativa privada porém, uma vez que este assunto merece a atenção de gestores públicos e planejamento em políticas públicas ambientais. O caráter independente de projetos como o da Reciclã revela novas formas de geração de renda seria preciso no entanto, mais investimento da iniciativa pública e a coordenação dessas mesmas políticas para a abertura de espaços sociais que serviriam como "vitrine” para essa nova forma de expressão da arte.

Além de servir como instrumento de auto-sustentabilidade, a produção de uma arte com especificidades (bonecas de sobras de malhas, objetos metálicos para decoração, jóias de cacos de vidro etc) está diretamente relacionada com o processo de criação e afirmação de identidades das comunidades carentes participantes do projeto. Normalmente, elas se sujeitam a um processo de aculturação promovido pela cultura de massa, 
através da mídia. $\mathrm{E}$ desconhecidas do resto da sociedade, essas comunidades são reiteradamente marginalizadas do processo social (produção e consumo, político e cultural).

O exame pormenorizado do projeto Reciclã e outras iniciativas similares podem servir de exemplo para demais comunidades também marginalizadas, como ocorre com grupos indígenas e populações ribeirinhas, ou mesmo em outras regiões empobrecidas do interior do Brasil. A aplicação simplificada das aulas nas oficinas de reciclagem favorece o processo de aprendizagem e a formação de agentes multiplicadores.

A valorização destas comunidades, bem como de suas regiões, acaba atraindo potenciais visitantes para comprar o artesanato e conhecer a história local.

Nesse sentido, o presente trabalho identificou e procurar articular os conceitos-chave, como: desenvolvimento sustentável, turismo sustentável, reciclagem, lixo, arte e inclusão social, dando voz aos agentes mobilizadores e comunidades. 


\section{REFERÊNCIA BIBLIOGRÁFICA}

\section{LIVRO:}

CAPRA, Fritjof; A Teia da Vida - Uma Nova Compreensão Científica dos Sistemas Vivos; Tradução para o Brasil: Editora Cultrix; São Paulo; 1996.

CAPRA, Fritjof; O Ponto de Mutação; Tradução para o Brasil: Editora Cultrix; São Paulo; 1982.

LIMA BEZERRA, Maria do Carmo de; FACCHINA, Marcia Maria e RIBAS, Otto. Agenda 21 Brasileira - Resultado da Consulta Nacional. Criada por decreto presidencial em 26/02/1997. Brasília MMA/PNUD, 2002.

MONTORO SIQUEIRA, Tânia (Organização). Cultura do Turismo: Desafios e Práticas Socioambientais. Brasília. Thesaurus Editora, 2003.

RIBEIRO, Sandra Bernades. Brasília: Memória, Cidadania e Patrimônio Cultural. São Paulo. Annablume. 2005.

SACHS, Ignacy. Desenvolvimento - Includente, Sustentável e Sustentado. São Paulo. Garamond/Sebrae. 2004.

TEIXEIRA, João Gabriel L. C.; CARVALHO GARCIA, Marcus Vinícius e GUSMÃO, Rita. Patrimônio Imaterial, Performance Cultural e (Re)tradicionalização. Brasília. ICS-UNB, 2004.

\section{REVISTA:}

ECO 21; Ano XIV; N 92; Julho 2004.

Horizonte Geográfico; Ano 17; № 95; Outubro 2004.

JB Ecológico; Ano 3; N³4; Novembro 2004 (Edição: toda quinta no Jornal do 
Brasil).

\section{ARTIGO:}

Cultura Sampler de Marcus Bastos, PROFEssor acadêmico do CURSO dE TECNOLOGIA E MídIAS dA PUC-SP. SEM REFERÊNCIA DE DATA.

\section{SITE:}

www.abipet.org.br(Informações sobre o setor de embalagens pets).

Www.anama.com.br (Informações sobre as atividades da Associação Nacional de Municípios e Meio Ambiente).

www.cempre.org.br(Informações sobre reciclagem e meio ambiente, eventos, mercado e cooperativas).

www.ecoambiental.com.br (Informações sobre meio ambiente com ênfase na área jurídica e apoio ao IAMAM - Instituto de Ações para o Meio Ambiente). www.ibge.gov.br(Instituto Brasileiro de Geografia e Estatística).

www.ibema.hpg.com.br(Instituto Brasileiro da Ecologia e Meio Ambiente).www.lixo.com.br (Artesanato de materiais recicláveis).

WWW.LIXOARTE.KIT.NET (Artesanto de materiais recicláveis).

www.meioambienteindustrial.com.br (Revista do Meio Ambiente).

www.reciclaveis.com.br (Informações sobre reciclagem).

www.reciclabrasiltv.com.br (Programa de TV: Recicla Brasil, veiculado na TV COM no estado de São Paulo e exibidos nos canais 14, 72 e 96).

www.reportereco.com.br (Site especializado em Ecologia, Educação Ambiental, Reciclagem, Ecoturismo e Mundo Animal). 


\section{AneXos}

1.1 -DADOS DOS ENTREVISTADOS E QUESTÕES ABORDADAS. FORAM entreVistados os idealizadores do Projeto Reciclã (HenRiQue Vila Verde E NiCOLE MONTEIRO) 


\section{ENTREVISTA 1:}

HeNRIQUe Vila Verde: ENTREVISTA REALIZADA NO DIA 04/05/2005, DOCUMENTADA POR EMAIL. FORMAÇÃO ACADÊMICA: PUBLICIDADE E propaganda. Atuante no Projeto Reciclã do qual faz parte há TRÊS ANOS.

\section{ENTREVISTA 2:}

Nicole Monteiro: Entrevista REAlizadA NO DIA 08/12/2004, DOCUMENTADA EM FITA K7. FORMAÇÃO ACADÊMICA: PUBLICIDADE E PROpaganda. Atualmente, DESENVOlVE tRabalhos de RECiClagem NO PROJETO RECICLÃ DESDE 2002.

\section{QUESTÕES ABORDADAS:}

1.O QUE É O PROJETO RECILCÃ?

2.COMO NASCEU O PROJETO?

3.QUANTO TEMPO TEM O PROJETO?

4.QUEM SÃO SEUS IDEALIZADORES?

5.QUAIS SÃO OS OBJETIVOS DO PROJETO?

6.QUAIS E QUANTAS SÃO COMUNIDADES ESTÃO ENVOLVIDAS NO PROJETO?

7.O QUE É MATÉRIA-PRIMA SOCIAL?

8.DE QUE MANEIRA AS COMUNIDADES PARTICPAM DO PROJETO?

9.RECEBEM INCENTIVOS GOVERNAMENTAIS E/OU PRIVADOS?

10.Como é o DESEnVolvimento do tRABALHo dE EDUCAÇÃo 
AMBIENTAL?

11.QUAIS SÃO OS PONTOS DE VENDA DO PRODUTO FINAL ACABADO?

12. CONSIDERAÇÃO FINAL (PONTOS IMPORTANTES QUE O ENTREVISTADO GOSTARIA DE COLOCAR).

ANEXos

1.2 - "A SUSTENTABILIDADE É A ÚNICA SAÍDA”; PUBLICAÇÃo DA REVISTA ECO 21, Junho de 2004. Entrevista com PaUlo Nogueira Neto, PRESIDENTE da FundaçÃo Florestal de SÃo PAUlo E VICE-PRESIDENTE do WWF-BRASIL 


\section{AneXos}

1.3 - "DossiÊ ReCICLAGEM"; PUBliCAÇÃo dA REVISTA HoRIZONTE GEOGRÁFICO, ANo 17, № 95, Edição ESPECIAL DE $17^{\circ}$ ANIVERSÁRIO, 2004. O MATERIAL DESTA REVISTA TRAZ BONS EXEMPLOS DE RECICLAGEM E EXEMPLOS DE HISTÓRIAS DE PESSOAS QUE CONSEGUEM LUCRAR COM A ATIVIDADE. 


\section{ANEXOS}

1.4 -Catálogo de Exposições: Do Lixo ao luxo; Realizada pela Casa AzUl Felipe Augusto (ASCA - Assistência Social Casa AzUl. Samambaia/DF) em PARCERIA COM A FUNDAÇÃo BANCO dO BRASIL. ESTA INSTITUIÇÃO ATENDE, POR DIA, CERCA DE 500 CRIANÇAS E ADOLESCENTES CARENTES. 
ANEXos

1.5 -Catálogo GeraçÃo ANOS 80, SOB UM OLHAR ESPECIaL À ObRa ViLA DAS TORRES (PERIFERIA de CuRItiba/PR) da ARTISTA PlÁstica Mônica Nador. A obra faz Parte do Projeto Paredes Pintadas e fol Realizada com a AJUda DOS PRÓPRIOS MORADORES DA COMUNIDADE VILA DAS TORRES EM CURITIBA, 2003. 
AnEXos

1.6 -"Mundo Precisa de Chacoalhão”; PUblicaÇão on-Line do JORNAL Folha de SÃo Paulo; SeÇÃo CIÊnCIA; 07/07/2003. EnTREVISTA REALIZADA COM O AMBIENTALISTA NORTE-AMERICANO LESTER BROWN, ATUALMENTE, CONSIDERADO UM DOS MAIS ENTENDIDOS NA ÁERA AMBIENTAL. 


\section{Mundo precisa de "chacoalhão", diz ambientalista CLAUDIO ANGELO - Ciência da Folha de S.Paulo}

Somente um evento catastrófico e repentino poderá colocar o planeta no rumo de uma economia ambientalmente sustentável. Esse "11 de setembro" ecológico deve acontecer nos próximos dois anos, na forma de uma alta maciça no preço dos alimentos causada pela queda na produção de grãos da China, resultado da degradação ambiental.

A previsão é de um dos ambientalistas mais respeitados do mundo, o americano Lester R. Brown, 69. Formado em economia agrícola, Brown fundou em 1973 o Worldwatch Institute, organização não-governamental responsável pela publicação anual do "Estado do Mundo", considerado a bíblia do pensamento ecológico.

Para o ambientalista, que hoje preside o Earth Policy Institute, em Washigton, a economia clássica gerou uma distorção nos preços ao ignorar os custos ambientais que agrava ano a ano a situação dos ecossistemas terrestres --que são, segundo ele, a própria base da economia.

No livro "Eco-Economia" que ganha hoje versão brasileira, Brown propõe a incorporação dos custos ambientais pela reestruturação do sistema tributário.

A idéia, que vigora em escala mínima em alguns países da Europa, é diminuir impostos sobre os ganhos e aumentar taxas sobre atividades destrutivas, como a queima de derivados do petróleo --principal fonte dos gases que causam 0 aquecimento global.

Brown reconhece que não é uma tarefa simples. Essa reestruturação, que abriria o caminho para energias limpas, como a eólica e o hidrogênio, dependeria de "uma mentalidade de mobilização como a que tivemos na $2^{\mathrm{a}}$ Guerra", obrigatoriamente disparada por um evento catastrófico. Especialmente nos EUA, país que mais pesa na balança ambiental do globo e que tem andado exatamente na contramão da "eco-economia", reduzindo impostos a atividades destrutivas.

Folha - No seu livro, o sr. diz que nós provavelmente não conseguiremos fazer as pessoas que tomam decisões econômicas pensarem como ecologistas. $O$ ambientalismo falhou em converter as pessoas? 
Lester R. Brown - Até agora, nós não fizemos um bom trabalho. Nós estamos gradualmente fazendo progressos. As pessoas estão conscientes dos principais problemas associados ao aquecimento global, como derretimento das geleiras, ondas de calor recordes, tempestades mais destrutivas. Há avanço, mas não chega nem perto do que seria necessário.

\section{Folha - E qual é o problema? Onde os ambientalistas têm errado?}

Brown - Na maior parte da nossa existência como espécie, nós não precisamos nos preocupar com o ambiente. Éramos poucos e nosso impacto era mínimo. Só cresceu a partir da agricultura e, em sua maior parte, após a Revolução Industrial. A economia mundial se expandiu sete vezes desde 1950. Agora nós temos de começar a pensar na relação entre a economia e os ecossistemas terrestres. Dois séculos atrás, nós pensamos mais no lado econômico, como desenvolver um mercado e criar empresas. E perdemos o pé da natureza da nossa dependência dos recursos naturais.

\section{Folha - Mas o sr. não acha que, em vez de atrair a atenção do público para esses problemas, não se está perdendo essa atenção?}

Brown - Meu palpite é que vamos precisar de um chacoalhão de algum jeito para nos fazer focalizar os problemas ambientais. Eu costumo usar o exemplo histórico dos EUA em 1941. Se você fizesse uma pesquisa de opinião com os americanos em 6 de dezembro de 1941 e perguntasse se eles achavam que os EUA deveriam se envolver na guerra, acho que 85\% teriam dito: "De jeito nenhum!" E aí veio o 7 de dezembro [o ataque a Pearl Harbour] e tudo mudou. E muito rápido.

Um mês depois do ataque a Pearl Harbour, o presidente Roosevelt disse que o país iria produzir 40 mil tanques, 65 mil aviões, 20 mil peças de artilharia antiaérea. A indústria automobilística disse que não conseguiria produzir armas e carros ao mesmo tempo. E ele disse: "Nós vamos suspender a produção de carros nos EUA." E foi exatamente o que ele fez. A indústria se redirecionou. Apesar de todas as evidências de que vamos ser forçados a essa guerra, a maioria das pessoas não querem aceitar até que recebamos um chacoalhão.

Folha - Um tipo de 11 de setembro ambiental.

Brown - Exatamente.

\section{Folha - E o que seria?}

Brown - O preço da comida. A escassez de água está se tornando um grande problema. Se há escassez de água, há escassez de comida. Minha aposta é que o chacoalhão virá com a China, cuja produção de grãos foi de 9 milhões de toneladas em 1950 para 390 milhões de toneladas em 1998, e agora caiu para 340 milhões de toneladas. No próximo ano ou dois, teremos 1,3 bilhão de consumidores chineses competindo no mercado com os consumidores americanos pelos grãos americanos. E esse 1,3 bilhão de chineses tem US $\$ 100$ 
bilhões de dólares de superávit comercial com os EUA.

Uma geração atrás simplesmente imporíamos um embargo às exportações para impedir o preço de subir. Mas, agora, temos interesse na estabilidade da China, porque a economia chinesa é o motor da economia mundial. Eu acho que nesse ponto, quando os preços dos alimentos subirem muito, começaremos a achar que há alguma coisa mudando. Isso será dramático se ficar claro, como eu acho que ficará, que as altas temperaturas estão reduzindo a produtividade.

Folha - Há dois pontos aí: primeiro, todas as previsões dos chamados "profetas do apocalipse", de altas nos preços de comida ao esgotamento das reservas de petróleo e a bomba populacional não se concretizaram. Por que deveríamos acreditar nelas desta vez?

Brown - Primeiro deixe-me dizer um par de coisas. Um, embora tenhamos pensado que, com a revolução verde e o aumento na tecnologia agrícola, a fome logo seria uma coisa do passado, ainda temos 800 milhões de pessoas que não têm comida. Há muita gente com fome. Eu não diria que as previsões falharam: elas se materializaram, esse é o problema! O clima está mudando, as temperaturas estão subindo. Está acontecendo! Pode ser um sonho ruim, mas está acontecendo.

Folha - Isso nos traz ao segundo ponto: como tornar clara a associação entre a queda na produtividade na China e a mudança climática? Há muita incerteza científica.

Brown - No último ano houve várias novas pesquisas sobre o efeito preciso da temperatura na produtividade das lavouras. A maioria dos modelos que têm sido usados para prever o efeito do aquecimento global na agricultura foram baseados em dados muitos gerais, sem informação específica. O que estamos obtendo agora do Instituto Internacional de Pesquisa do Arroz nas Filipinas e do Serviço de Pesquisa Agrícola dos EUA é que o aumento de $1^{\circ} \mathrm{C}$ acima do nível ótimo durante a fase de crescimento reduz a produtividade em 10\%. Então, podemos olhar para lavouras cuja produtividade foi reduzida pelo aumento de temperatura com um grau de confiança maior.

Folha - O sr. diz também que nós não vamos chegar a lugar nenhum numa eco-economia com um projeto aqui e outro ali. Os ambientalistas e as ONGs têm falhado em dar escala a pequenos projetos. Não está na hora de fazê-los pensar como economistas?

Brown - Acho que sim. Acho que precisamos pensar em mudança sistêmica. Essa mudança significa lidar com coisas como subsídios e taxas sobre atividades destrutivas. Acho que a medida política mais importante para construir uma ecoeconomia é reestruturar o sistema tributário. Baixar os impostos sobre o ganho e aumentar os impostos sobre atividades como a emissão de carbono.

Impostos ambientais são impopulares. Como conciliar ganhos ambientais de 
longo prazo com perdas políticas de curto prazo?

Brown - Houve muito poucos esforços para reestruturar o sistema tributário. Na Europa, oito ou dez países começaram a reestruturar seu sistema tributário, mas de uma maneira muito modesta, talvez afetando $2 \%$ ou $5 \%$ de sua base tributária. Mas está funcionando, serve de modelo para outros países e eles estão fazendo isso mais e mais.

Folha - Mas o país que mais pesa na questão são os EUA, e eles estão longe de fazer essa mudança.

Brown - Sim. Tão longe quanto estávamos de entrar numa guerra em 6 de dezembro de 1941.

Folha - Os economistas clássicos argumentarão que, se todos os fatores externos, como os ambientais, forem incluídos nas contas da economia, os preços subirão a ponto de tornar as relações econômicas impraticáveis.

Brown -Se eles estiverem certos, então nós estamos com problemas. Porque nós pagaremos esses custos de um jeito ou de outro. Por exemplo, neste país, um ano atrás, os Centros de Controle de Doenças publicaram uma análise sobre os custos sociais do cigarro. Concluíram que, baseado no custo adicional do tratamento médico e da redução de produtividade por faltas no trabalho, o custo para a sociedade de um maço de cigarros é US\$7,18. Esse é o custo indireto. Ele é real. Alguém paga por ele: o empregador, o empregado ou a sociedade. E o mesmo acontece com a mudança climática. Nós vamos pagar o custo indireto de queimar um galão de gasolina, na forma de poluição do ar, tratamentos médicos, tempestades mais violentas etc.

Folha - O cigarro é uma propriedade. A atmosfera é um bem comum. Como fazer para pôr uma etiqueta de preço num bem comum e legislar sobre ele?

Brown - É difícil. Muito mais difícil porque a principal pessoa que paga o custo de fumar um cigarro é o fumante. E a principal pessoa que paga o custo de queimar um galão de gasolina não é necessariamente o motorista. Pode ser um plantador de arroz em Bangladesh, cujas terras estão sendo inundadas devido ao aumento do nível do mar.

Folha - E qual é a solução?

Brown - Fazer com a gasolina o que os Centros para Controle de Doenças fizeram com os cigarros: detalhar os custos indiretos e aí reestruturar o sistema tributário.

Folha - Mas, para funcionar, a abordagem precisa ser global, e soluções globais não parecem muito na moda hoje. 
Brown - É verdade. Mas não precisa ser inteiramente global, precisa ter o envolvimento de vários países em várias medidas. A questão interessante é: o custo para a sociedade de queimar um galão de gasolina é maior ou menor do que o custo de fumar um maço de cigarros? Meu palpite é: se incluirmos todos os custos indiretos, o da gasolina é mais alto. Por exemplo: o Banco Mundial previu que, se o nível do mar subir um metro, Bangladesh perde metade de sua área de cultivo de arroz e 40 milhões de bengaleses serão deslocados. Qual é o custo de assentar essas pessoas? São custos tão grandes que nós não queremos nem contemplá-los. 